\title{
Meta-Analysis of the Efficacy and Adverse Reactions of Ibrutinib in the Treatment of Refractory/Relapsed Mantle Cell Lymphoma
}

\author{
Mei Cao ${ }^{1,2}$, Yansong $\mathrm{Tu}^{3 *}$, Xiaoyan Jiang1, Xuekun Wang1,2, Yazhi Yang1, Xiaoyan Zhang1,4, \\ Huaijun $\mathrm{Tu}^{5}$, Jian $\mathrm{Li}^{1 \#}$
}

${ }^{1}$ The Key Laboratory of Hematology of Jiangxi Province, The Department of Hematology, The Second Affiliated Hospital of Nanchang University, Nanchang, China

${ }^{2}$ Graduate School of Medicine, Nanchang University, Nanchang, China

${ }^{3}$ Faculty of Environment, University of Waterloo, Waterloo, Canada

${ }^{4}$ Laboratory of Infection \& Immunology, School of Basic Medical Sciences, Nanchang University, Nanchang, China

${ }^{5}$ The Department of Neurology, The Second Affiliated Hospital of Nanchang University, Nanchang, China

Email: "ndefy03048@ncu.edu.cn

How to cite this paper: Cao, M., Tu, Y.S., Jiang, X.Y., Wang, X.K., Yang, Y.Z., Zhang, X.Y., Tu, H.J. and Li, J. (2021) Meta-Analysis of the Efficacy and Adverse Reactions of Ibrutinib in the Treatment of Refractory/Relapsed Mantle Cell Lymphoma. Open Journal of Preventive Medicine, 11, 369-382. https://doi.org/10.4236/ojpm.2021.119029

Received: June 27, 2021

Accepted: September 27, 2021

Published: September 30, 2021

Copyright $\odot 2021$ by author(s) and Scientific Research Publishing Inc. This work is licensed under the Creative Commons Attribution International License (CC BY 4.0).

http://creativecommons.org/licenses/by/4.0/ (c) (i) Open Access

\begin{abstract}
Objective: Therapeutic results of relapsed/refractory mantle cell lymphoma (R/R MCL) are very disappointing at present, and there is no standard effective treatment regimen. Ibrutinib has been proved to be effective for $R / R$ MCL, however, the sample size of these individual clinical studies was relatively small. Hence, current clinical experience in its usage is still limited. It is necessary to systematically analyze the efficacy and adverse reactions of ibrutinib in the treatment of R/R MCL. Methods: The PubMed, Cochrane Library, and Embase databases were searched using English search terms, mantle cell lymphoma, MCL, and ibrutinib; the VIP, Wanfang, and China National Knowledge Infrastructure (CNKI) databases were searched using the Chinese search terms, ibrutinib and mantle cell lymphoma. The extracted data were subjected to meta-analysis using $\mathrm{R}$ software to deduce the effective rate and occurrence rate of serious adverse reactions. Results: A total of 12 cohort studies were included in this analysis. The results demonstrated that ibrutinib could be an efficient therapy regimen for R/R MCL patients and the effect of combination therapy was better than that of single-drug therapy. During the treatment with ibrutinib, the adverse reactions mainly included hematological toxicity, infection, atrial fibrillation, and bleeding. Discussion: Our analysis showed ibrutinib is an optimal second-line treatment for $R / R$
\end{abstract}

${ }^{\star} \mathrm{M}$. Cao and Y.S. Tu contribute equally to this study and share first authorship.

${ }^{*}$ Corresponding author. 
MCL, and the combination therapy is more effective than monotherapy as it was well-tolerated by the patients. Therefore, the combination of other drugs for R/R MCL should be considered for patients with poor efficacy of ibrutinib alone or relapse after treatment.

\section{Keywords}

Mantle Cell Lymphoma, Ibrutinib, Meta-Analysis

\section{Introduction}

Mantle cell lymphoma (MCL) is a malignant tumor derived from B lymphocytes. It is an invasive and refractory disease that progresses rapidly, and the long-term survival rate is low [1]. The genetic basis of MCL pathogenesis is the abnormality of chromosome $t(11 ; 14)$ ( 113 ; q32), which elevates the expression of Cyclin D1 and the cell cycle disorder [2]. Although some patients with MCL responded to multi-drug combination chemotherapy, such as R-CHOP (rituximab, cyclophosphamide, Adriamycin, vincristine and prednisone) at the initial diagnosis, relapse was common, and the subsequent prognosis was poor. Currently, there is no standard effective treatment regimen, and the common chemotherapeutic regimens exhibit adverse reactions, which could lead to bone marrow suppression [3] [4]. Thus, study new drugs with low toxicity and improved efficacy.

Bruton's tyrosine kinase (BTK) is a key enzyme in the B cell receptor (BCR) signaling pathway and plays a critical role in the occurrence and development of MCL [5]. Inhibiting BTK in B-cell malignancies could slow the growth and proliferation of tumor cells; thus, it is deemed as a unique therapeutic target [6]. The BTK inhibitor ibrutinib covalently binds to a cysteine residue (Cys-481) in the ATP binding domain of the BTK active site to inhibit the activity of this enzyme, thereby inhibiting the BCR signal transduction, and inhibiting the proliferation, survival, adhesion, and migration of tumor cells [7] [8]. Clinical studies have confirmed that ibrutinib is an effective drug for R/R MCL and was a major breakthrough in the history of MCL treatment. In 2013, the US FDA approved ibrutinib for the treatment of R/R MCL. Several clinical studies have shown the efficacy of the drug. For example, Dreyling et al. [9] conducted a phase 3 randomized controlled trial to compare the efficacy of ibrutinib and temsirolimus in the treatment of R/R MCL. The study included 280 patients with R/R MCL, including 139 patients in the ibrutinib group and 141 patients in the temsirolimus group. The results showed that the overall response rate (ORR) was $72 \%$, and the complete remission rate (CR) was $19 \%$, which was significantly higher than the ORR (40\%) and CR (1\%) of the temsirolimus group. Wang et al. [10] recruited 120 patients with R/R MCL in the study to evaluate the therapeutic effect of ibrutinib, and showed that the ORR was $62.7 \%$, and CR was $20.9 \%$. Although ibrutinib achieved a specific effect in the treatment of R/R MCL, adverse reac- 
tions, such as bleeding and atrial fibrillation, also occurred during the treatment. The study by Dreyling et al. [9] showed that the occurrence rate of atrial fibrillation $\geq$ grade 3 and bleeding $\geq$ grade 3 was $4 \%$ and $10 \%$, respectively and the study by Wang et al. [10] showed that the occurrence rate of atrial fibrillation $\geq$ grade 3 and bleeding $\geq$ grade 3 was $10.8 \%$ and $2 \%$, respectively.

However, the sample size of these individual clinical studies was relatively small, and the results of each clinical study differed due to the variety of definite or uncertain factors. Hence, some clinicians were concerned about the treatment of R/R MCL with ibrutinib, deeming it necessary to conduct a comprehensive systematic analysis of the existing clinical research results on larger sample size and evaluate the clinical efficacy and adverse reactions of ibrutinib in the treatment of R/R MCL, as well as provide guidance for clinical medication.

\section{Materials and Methods}

\subsection{Materials}

The literature of clinical studies on ibrutinib in the treatment of R/R MCL before December 1, 2019, was retrieved. The inclusion criteria were as follows: 1) The subjects were $>18$-year-old; 2) Patients with refractory or relapsed MCL; 3) The treatment regimen was ibrutinib alone or in combination with other drugs; 4) The observation indicators included ORR, CR, two-year progression-free survival (PFS) rate, two-year overall survival (OS) rate, and the occurrence rate of serious adverse reactions ( $\geq$ grade 3 neutropenia, hemoglobin reduction, thrombocytopenia, infection, atrial fibrillation, and bleeding); 5) If several articles were in the same cohort study, only the results of the last update were included. The exclusion criteria were as follows: 1) MCL patients with initial treatment; 2) $\mathrm{Pa}$ tients with tumors other than MCL; 3) Patients with MCL who relapsed after prior hematopoietic stem cell transplantation treatment; 4) The sample size was small $(\mathrm{n}<10)$; 5) The data were incomplete.

\subsection{Methods}

\subsubsection{Literature Search Methods}

The databases in English were searched using the terms, mantle cell lymphoma, MCL, and ibrutinib. The Chinese databases were searched using the Chinese search terms, mantle cell lymphoma and ibrutinib. Also, the subject term and free word search were conducted, and all relevant literature was retrieved to avoid errors caused by excluding any literature.

\subsubsection{Data Extraction and Quality Evaluation of Literature}

Two investigators searched the Chinese and English databases using the above search terms and read the titles and abstracts of the literature according to the inclusion and exclusion criteria listed above; the full-text of the articles was read for screening if necessary. Finally, the data of the included literature were extracted, and the quality was evaluated. All the above steps were completed independently. In case of any disagreement, a consensus was reached through dis- 
cussion, and a third-party judgment was approached if necessary. The extracted data included the author of the literature, the number of patients, the time of publication, intervention measures, age, and some indicators to evaluate the efficacy and adverse reactions.

\subsubsection{Statistical Methods}

$\mathrm{R}$ software was used for meta-analysis of the extracted data. The $\chi^{2}$ test was used to evaluate the heterogeneity of the included literature. $P<0.1$ indicated heterogeneity between the included literature results, which was assessed by the random effect model. If there was no heterogeneity or if heterogeneity was relatively small, the fixed-effect model was used, and $\vec{I}^{2}$ was an indicator that reflected the degree of heterogeneity between multiple research results. Typically, heterogeneity was considered when $P^{2}>50 \%$, no heterogeneity when $P^{2}<25 \%$, the heterogeneity was low when $P^{2}$ was $25 \%-0 \%$, greater heterogeneity when $P^{2}$ was 50\% - 75\%, and significant heterogeneity when $P^{2}>75 \%$. Combining $P$-value and $I^{2}$ value, it could be considered that if $P^{2} \geq 50 \%$ or $P \leq 0.10$ and $P^{2}>25 \%$, it could be inferred that there was statistical heterogeneity; if $P^{2} \leq 25 \%$ or $P>0.10$ and $I^{2}$ $<50 \%$, it could be inferred that the heterogeneity was small and could be ignored. Each effect size was expressed as a $95 \%$ confidence interval (CI, the statistical significance level was set at $\alpha=0.05$, and sensitivity analysis was performed if necessary [11].

\subsubsection{Publishing Bias}

The reliability of meta-analysis results was affected by publication bias, and hence, publication bias analysis was carried out on the included studies. Funnel chart was an intuitive method to evaluate the publication bias. If the included studies had publication bias, the funnel chart was asymmetric, and the more obvious the asymmetry, the greater the publication bias. However, no publication bias was reported if the funnel chart was symmetric.

\section{Results}

\subsection{Literature Search Results}

A total of 1800 articles were retrieved from the database, including 1564 in English and 236 in Chinese; 1366 articles were remaining after 434 duplicate documents were excluded. After reading the titles and abstracts, 1289 articles irrelevant to the research topic were removed, and the remaining 77 were retained. Then, 65 articles were removed after reading the full text, including 14 due to incomplete data, 1 was a case report, 8 were reviews, 15 articles as they were same source of a cohort study, next, 7 articles were excluded as they follow an unqualified therapeutic regimen, 3 due to small sample size $(\mathrm{n}<10)$, 6 due to unqualified research model (cell lines research), 6 were retrospective analyses, 4 described unqualified outcome indicators, and 1 study was at the recruitment stage. Finally, 12 articles, in English, were recruited. The study selection process is shown in Figure 1. 


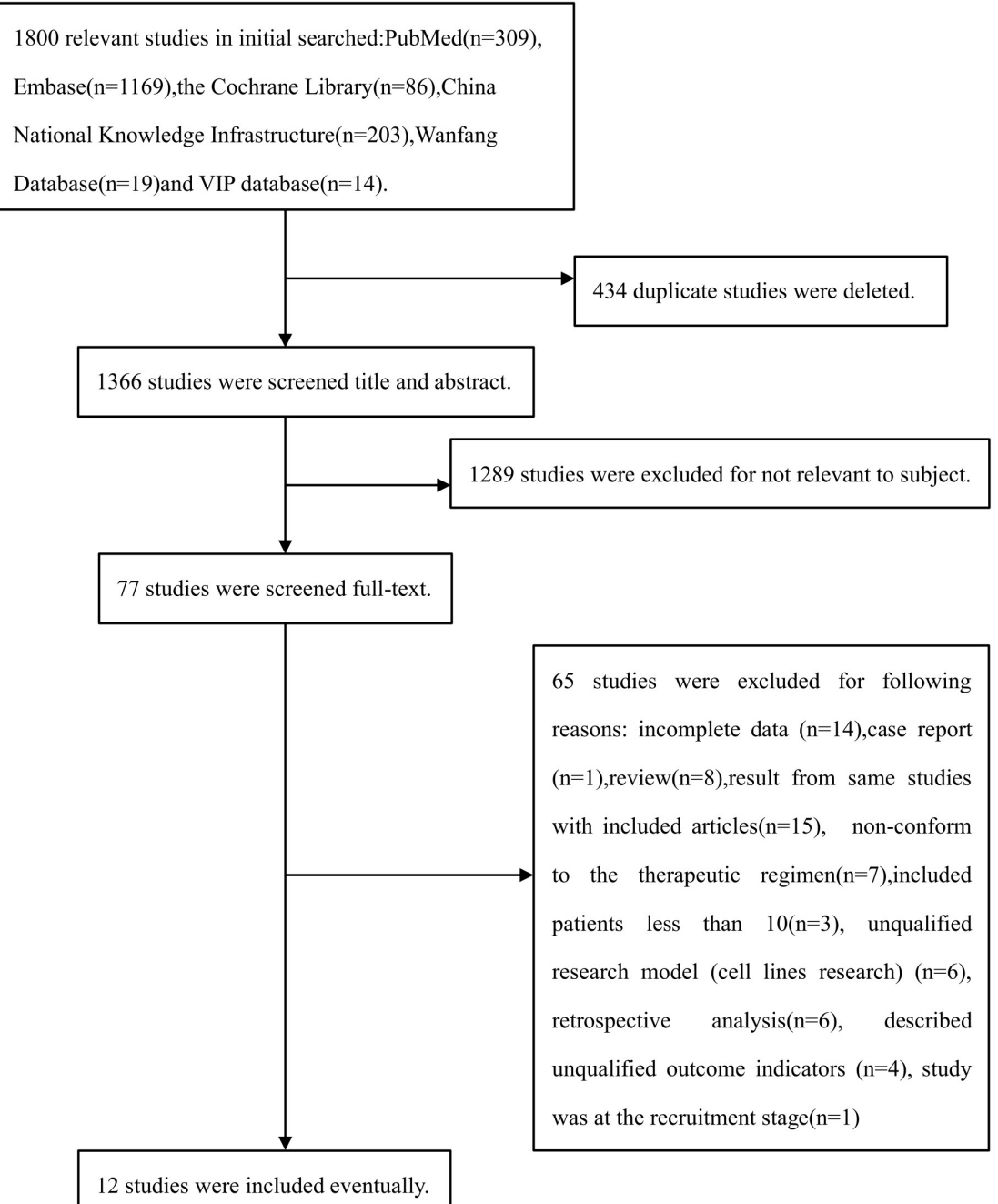

Figure 1. Flow chart of studies selection process.

\subsection{Baseline Information and Methodological Quality Evaluation of the Included Literature}

The 12 articles were cohort studies of refractory or relapsed MCL treated with ibrutinib alone or in combination with other drugs. The basic information was extracted from the included studies, including author, publication date, number of patients, age, treatment regimen, and outcome indicators (Table 1). The baseline data of the 12 studies were similar, and the literature quality was $>5$ points, which was deemed as satisfactory.

\subsection{Meta-Analysis Results}

\subsubsection{Publication Bias Assessment}

$\mathrm{R}$ software was used to test the publication bias of the 12 included articles. The funnel chart (Figure 2) indicated basic symmetry but no publication bias.

\subsubsection{Evaluation of Efficacy}

1) ORR (CR + Partial Remission (PR)) 


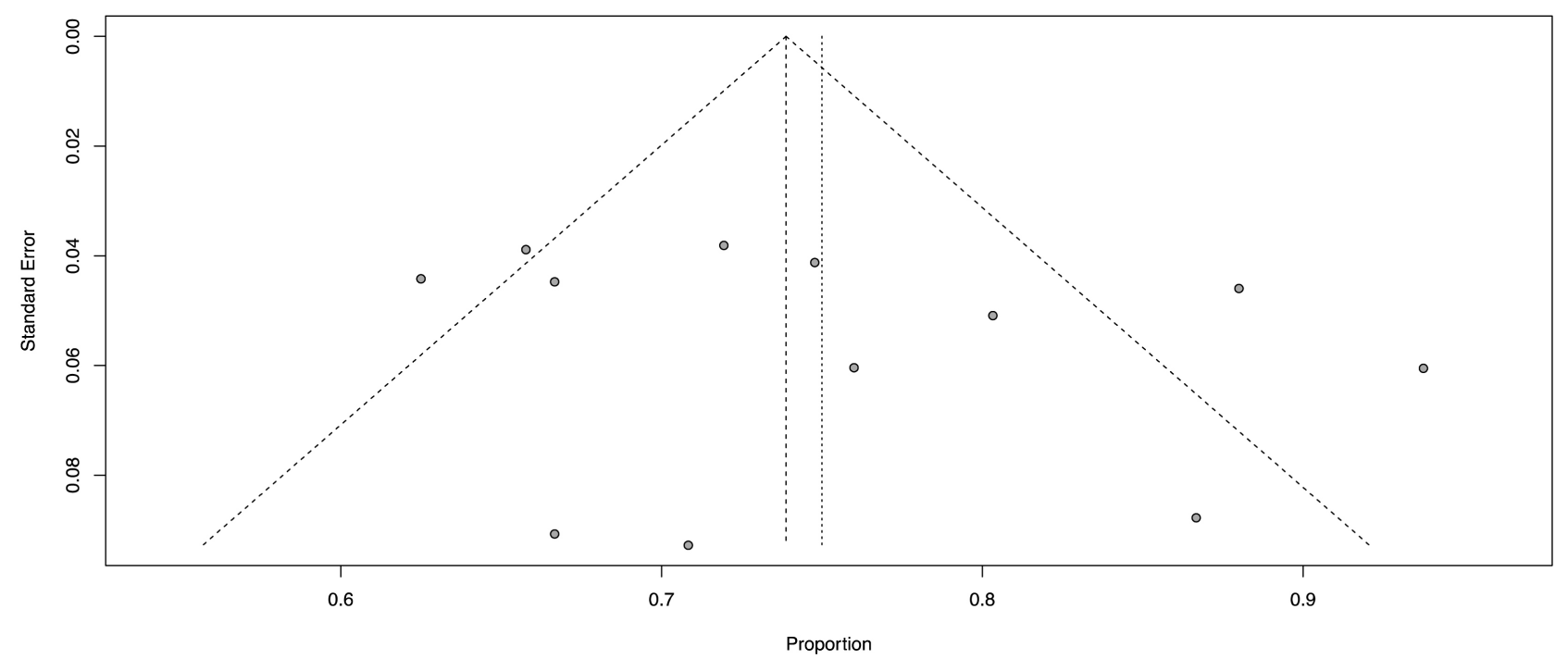

Figure 2. Funnel chart.

Table 1. Baseline characteristics of the included literature.

\begin{tabular}{|c|c|c|c|c|c|c|}
\hline Author & $\begin{array}{l}\text { Publication } \\
\text { time }\end{array}$ & $\begin{array}{l}\text { Research } \\
\text { type }\end{array}$ & $\begin{array}{l}\text { Mean age } \\
\text { (years) }\end{array}$ & Therapeutic regimen & $\begin{array}{l}\text { Median number of } \\
\text { prior treatment }\end{array}$ & $\begin{array}{l}\text { Number } \\
\text { of patients }\end{array}$ \\
\hline Dreyling M et al. [9] & 2015 & Cohort & 68 & Ibrutinib & $2(1-9)$ & 139 \\
\hline Wang ML et al. [4] & 2015 & Cohort & $68(40-84)$ & Ibrutinib & $3(1-5)$ & 111 \\
\hline Martin P et al. [12] & 2019 & Cohort & $65(42-81)$ & Ibrutinib + palbociclib & $1(1-5)$ & 27 \\
\hline Wang ML et al. [3] & 2015 & Cohort & $67(45-86)$ & Ibrutinib + rituximab & $3(1-9)$ & 50 \\
\hline Jerkeman M et al. [13] & 2018 & Cohort & $69(45-85)$ & Ibrutinib + lenalidomide + rituximab & $2(1-7)$ & 50 \\
\hline Martin P et al. [14] & 2019 & Cohort & l & Ibrutinib & $3(1,15)$ & 149 \\
\hline Wang M et al. [10] & 2014 & Cohort & $67.5(35-85)$ & Ibrutinib & $2(1-8)$ & 120 \\
\hline Jurczak W et al. [15] & 2013 & Cohort & 68 & Ibrutinib & $3(-)$ & 111 \\
\hline Maruyama D et al. [16] & 2019 & Cohort & $72(55-83)$ & Ibrutinib & $2.5(1-4)$ & 16 \\
\hline Tam CS et al. [17] & 2018 & Cohort & $68(47-81)$ & Ibrutinib + venetoclax & $2(1-6)$ & 24 \\
\hline Sharman JP et al. [18] & 2015 & Cohort & $71(55-80)$ & Ibrutinib + Ublituximab & $3(1-8)$ & 15 \\
\hline Tucker D et al. [19] & 2016 & Cohort & $67(48-90)$ & Ibrutinib & $3(1-6)$ & 61 \\
\hline
\end{tabular}

The ORR of ibrutinib in the treatment of R/R MCL was assessed in 11 studies. The total number of patients was 724 , the number of patients treated with ibrutinib alone was 558, and the number of patients treated with ibrutinib combined with other drugs (palbociclib/rituximab/lenalidomide + rituximab/venetoclax/ ublituximab) was 166. The included studies showed large heterogeneity; hence, the random effect model was used. The results of 11 studies showed that the ORR of ibrutinib was 76\% (95\% CI: $70 \%-82 \%, I^{2}=70 \%, P<0.01$ ), the ORR of ibrutinib alone was 74\% (95\% CI: 67\% - 82\%, $I^{2}=77 \%, P<0.01$ ), and the ORR of ibrutinib combined with other drugs was $81 \%$ (95\% CI: $75 \%-87 \%, I^{2}=44 \%$, $P=0.13)$. The effect of combination therapy was better than that of monotherapy. The specific results are shown in Figure 3. 


\section{2) Complete Remission (CR) Rate}

The CR of ibrutinib was 34\% (95\% CI: $26 \%-45 \%, I^{2}=84 \%, P<0.01$ ), the CR of ibrutinib monotherapy was $26 \%$ (95\% CI: $20 \%-34 \%, I^{2}=70 \%, P<0.01$ ), and the CR of ibrutinib combination therapy was $50 \%$ (95\% CI: $40 \%-63 \%, P=48 \%$, $P=0.1)$. The effect of combination therapy was better than that of monotherapy. The specific results were as follows (Figure 4).
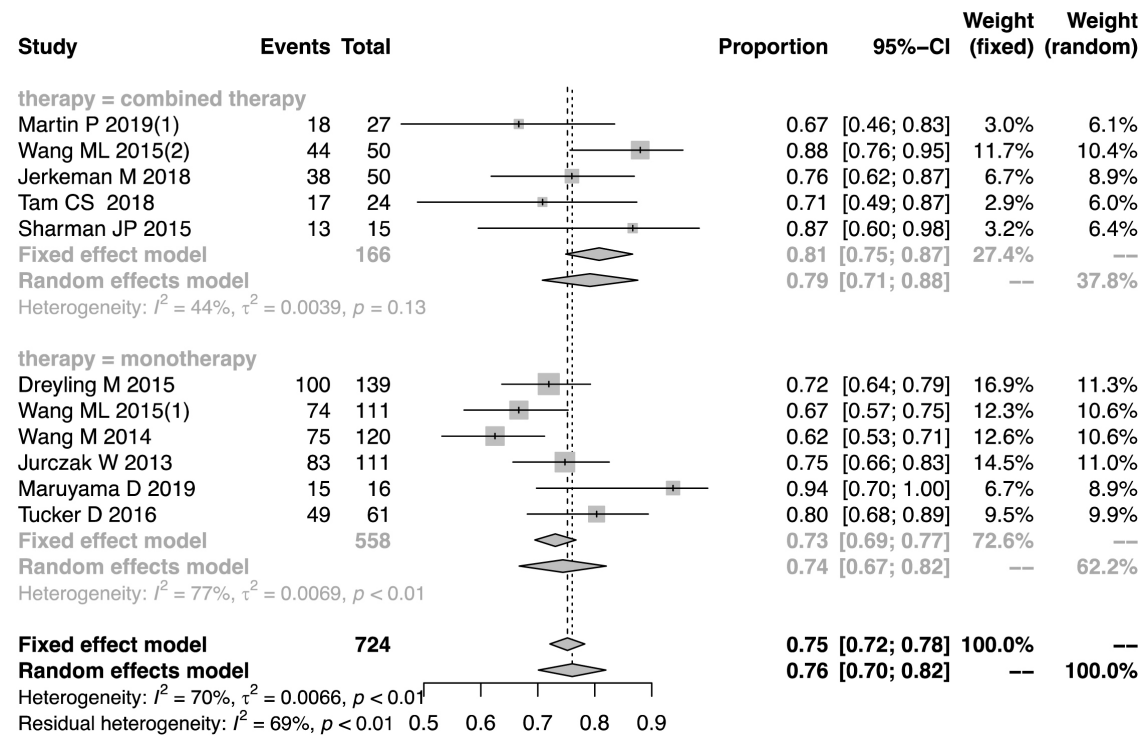

Figure 3. ORR of ibrutinib in the treatment of R/R MCL patients. The ORR of ibrutinib in the treatment of R/R MCL was $76 \%$ (95\% CI: 70\% - 82\%, $\left.P^{2}=70 \%, P<0.01\right)$, the ORR of ibrutinib alone was $74 \%$ (95\% CI: $67 \%-82 \%, P^{2}=77 \%, P<0.01$ ), and the ORR of ibrutinib combined with other drugs was $81 \%$ (95\% CI: $75 \%-87 \%, P^{2}=44 \%, P=0.13$ ).

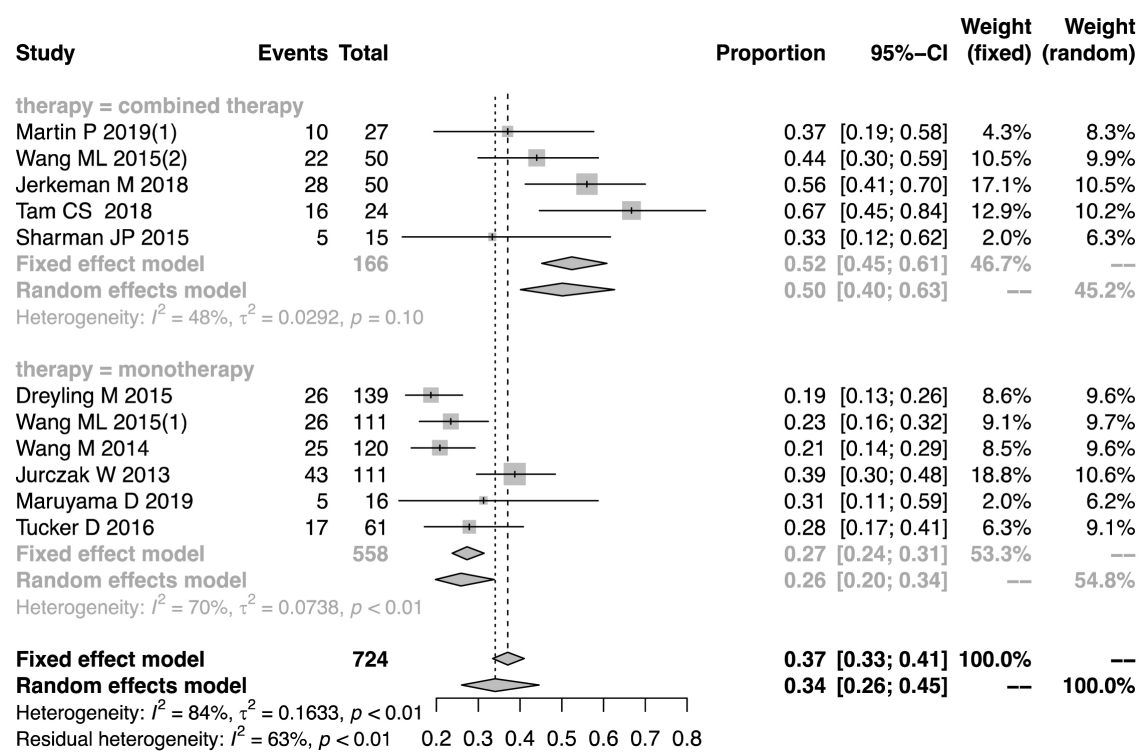

Figure 4. CR of ibrutinib in the treatment of R/R MCL patients. The CR of ibrutinib in the treatment of R/R MCL was $34 \%$ (95\% CI: $26 \%-45 \%, P=84 \%, P<0.01$ ), the CR of ibrutinib monotherapy was $26 \%$ (95\% CI: $20 \%-34 \%, P=70 \%, P<0.01)$, and the CR of ibrutinib combination therapy was 50\% (95\% CI: 40\% - 63\%, $P=48 \%, P=0.1$ ). 


\section{3) Two-Year PFS Rate}

The two-year PFS rate of R/R MCL patients treated with ibrutinib was evaluated in 4 studies, including 1 of combination therapy in 27 patients and 3 of monotherapy in 266 patients; since, heterogeneity was detected among the groups $\left(P^{2}=69 \%, P=0.02\right)$, random effect model was used. The results showed that the two-year PFS rate of ibrutinib in the treatment of R/R MCL patients was $41 \%$ (95\% CI: $31 \%$ - 54\%), and the two-year PFS rate of combination therapy group was $59 \%$ ( $95 \%$ CI: $43 \%-81 \%$ ), which was significantly higher than $37 \%$ of the monotherapy group $37 \%$ (95\% CI: $32 \%-44 \%, P^{2}=28 \%, P=0.25$ ), indicating that the combination therapy could achieve a higher two-year PFS rate than the monotherapy (Figure 5).

\section{4) Two-Year OS Rate}

The two-year OS rate of R/R MCL patients treated with ibrutinib was evaluated in 3 studies: 1 study of combination therapy with 27 patients, and 2 studies of monotherapy with 127 patients. The heterogeneity among the groups was small $\left(F^{2}=0 \%, P=0.81\right)$, and hence, the random effect model was used. The results showed that the two-year OS rate of ibrutinib in the treatment of R/R MCL patients was $49 \%$ (95\% CI: $41 \%$ - 57\%), and the two-year OS rate of combination therapy group was 59\% (95\% CI: $40 \%-77 \%)$, which was significantly higher than $47 \%$ (95\% CI: $38 \%-56 \%, P=0 \%, P=0.81$ ) of the monotherapy group, indicating that the combination therapy had a higher two-year OS rate than monotherapy (Figure 6).

\subsubsection{Analysis of Adverse Reactions}

Hematological toxicity (neutropenia, hemoglobin reduction, and thrombocytopenia) was a common adverse effect during the treatment of ibrutinib. The hematological toxicity statistics were performed on the included studies. Consequently, the occurrence rate of neutropenia $\geq$ grade 3 was $17 \%$ (95\% CI: $12 \%$ $\left.25 \%, P^{2}=82 \%, P<0.01\right)$, while the occurrence rate of thrombocytopenia $\geq$ grade

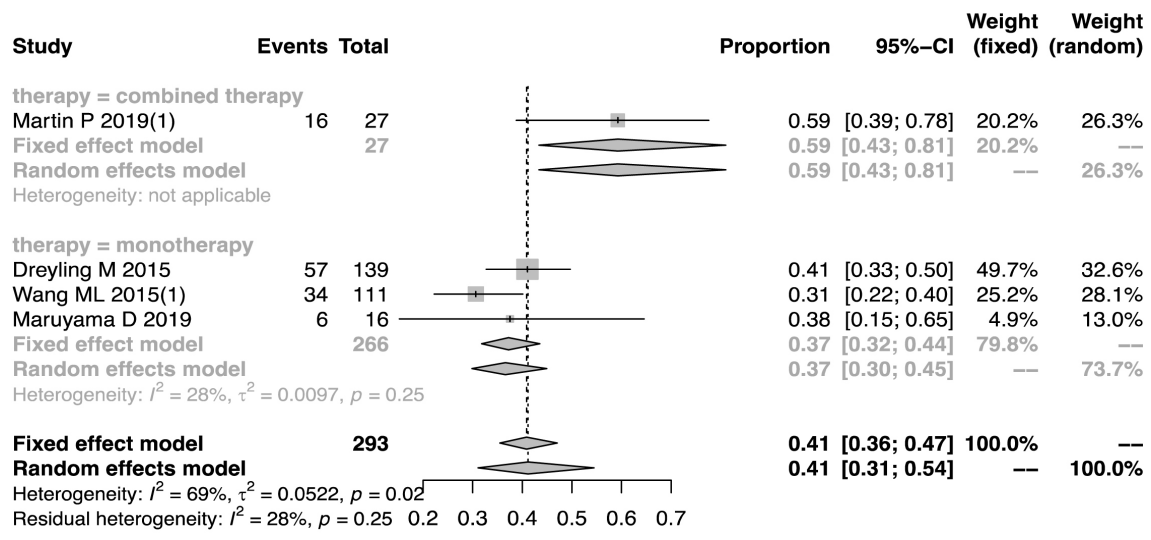

Figure 5. Two-year PFS rate of ibrutinib in the treatment of R/R MCL patients. The two-year PFS rate of ibrutinib in the treatment of R/R MCL patients was $41 \%$ (95\% CI: $31 \%-54 \%$ ), and the two-year PFS rate of combination therapy group was 59\% (95\% CI: $43 \%-81 \%$ ), which was significantly higher than $37 \%$ of the monotherapy group $37 \%$ (95\% CI: $32 \%-44 \%, P^{2}=28 \%, P=0.25$ ). 


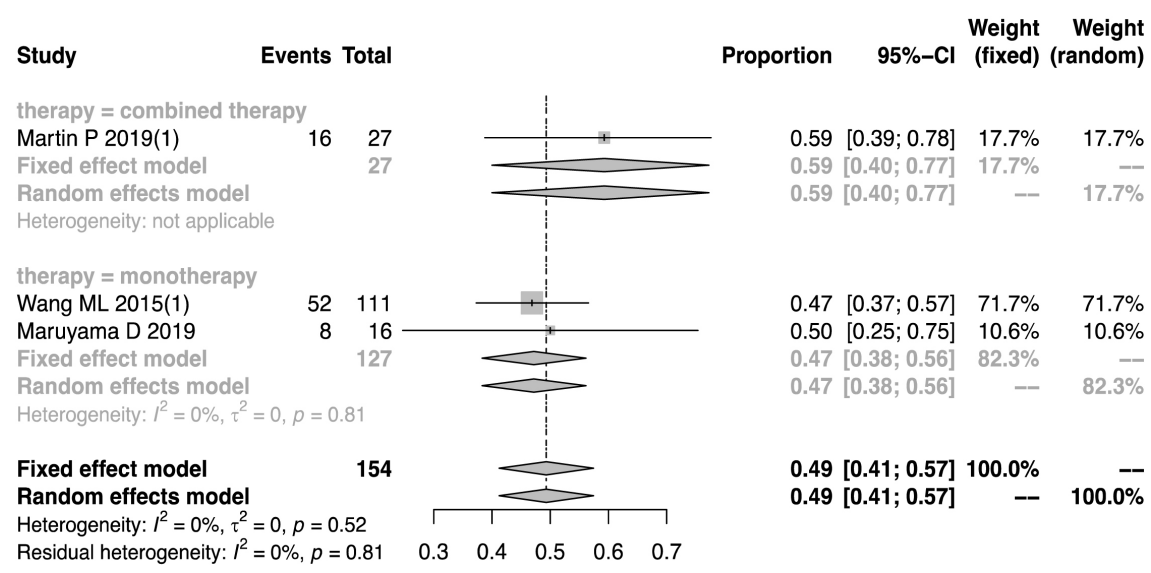

Figure 6. Two-year OS rate of ibrutinib in the treatment of R/R MCL patients. The two-year OS rate of ibrutinib in the treatment of R/R MCL patients was $49 \%$ (95\% CI: $41 \%-57 \%$ ), and the two-year OS rate of combination therapy group was 59\% (95\% CI: $40 \%-77 \%)$, which was significantly higher than $47 \%$ (95\% CI: $38 \%-56 \%$, I2 $=0 \%, P=$ 0.81 ) of the monotherapy group.

3 (12\% (95\% CI: 7\% - 17\%, $\left.\left.P^{2}=75 \%, P<0.01\right)\right)$ and anemia $\geq$ grade $3(6 \%(95 \%$ CI: $\left.3 \%-9 \%, P^{2}=80 \%, P<0.01\right)$ was lower than that of neutropenia, respectively. Previous studies reported that ibrutinib treatment increases the occurrence rate of infection, atrial fibrillation, and bleeding. Because the occurrence rate of such adverse reactions was not clear and that of the individual study event was relatively small, the statistical analysis of the included studies was performed. The results showed that the occurrence rate of infection $\geq$ grade 3 was $18 \%$ (95\% CI: $\left.12 \%-27 \%, I^{2}=63 \%, P=0.03\right)$, the occurrence rate of atrial fibrillation $\geq$ grade 3 was $6 \%$ (95\% CI: $\left.4 \%-9 \%, P^{2}=49 \%, P=0.05\right)$, and the occurrence rate of bleeding $\geq$ grade 3 was $4 \%$ (95\% CI: $\left.2 \%-6 \%, I^{2}=52 \%, P=0.04\right)$. The specific results are shown in Figure 7.

\section{Discussion}

Although some treated MCL responded to first-line combined chemotherapy, relapse was common, and the prognosis of patients with relapse was very poor [20]. However, currently, no uniform standard effective treatment regimen is available for R/R MCL patients. New drugs available for R/R MCL include ibrutinib, temsirolimus, lenalidomide, and bortezomib [21]. Some studies have reported that the ORR and CR rates of ibrutinib in the treatment of R/R MCL were higher than those of any other single drug, which is a major breakthrough in the treatment of R/R MCL [21] [22]. Although ibrutinib has been reported to be efficacious in the treatment of R/R MCL, some differences are noted in the results due to various factors. Therefore, this study systematically analyzed 12 articles to evaluate the efficacy and safety of ibrutinib in the treatment of MCL. The results showed that the ORR (CR + PR) was 76\% (95\% CI: 70\% - 82\%), and the heterogeneity $\left(I^{2}=70 \%, P<0.01\right)$ was high. Based on the comprehensive analysis, the heterogeneity might be high due to different drug regimens, and hence, 


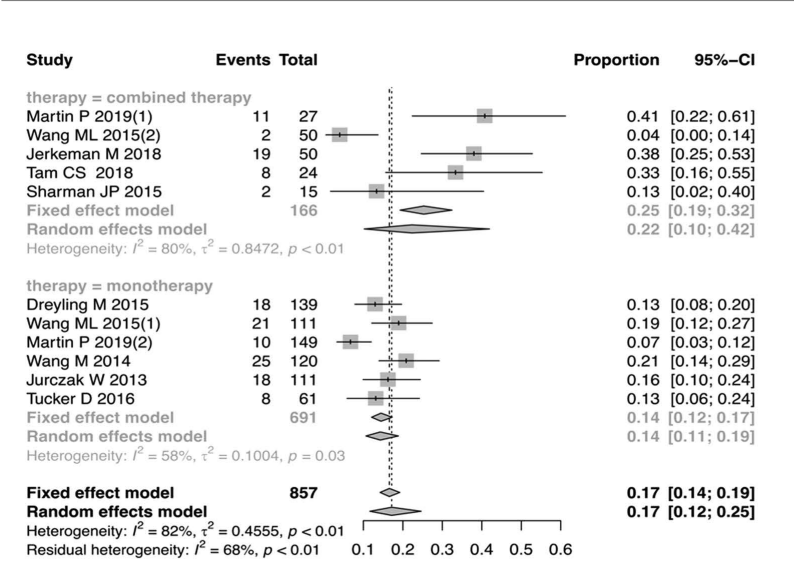

Occurrence rate of neutropenia $\geq$ grade 3

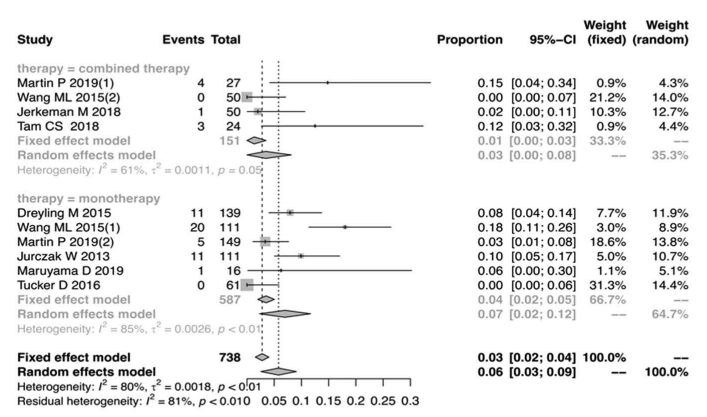

Occurrence rate of hemoglobin reduction $\geq$ grade 3

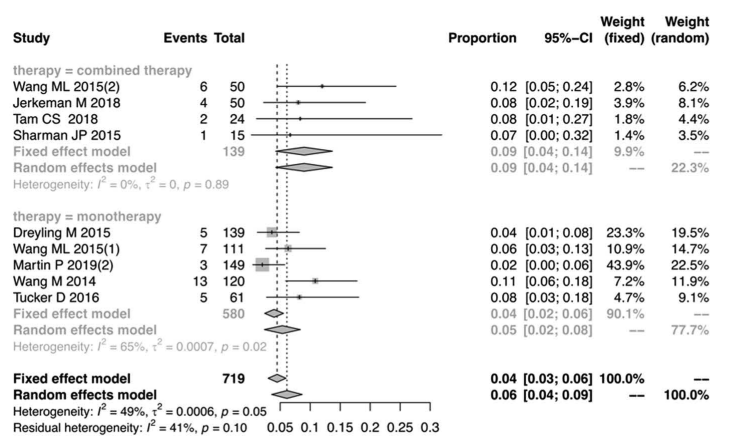

Occurrence rate of atrial fibrillation $\geq$ grade 3

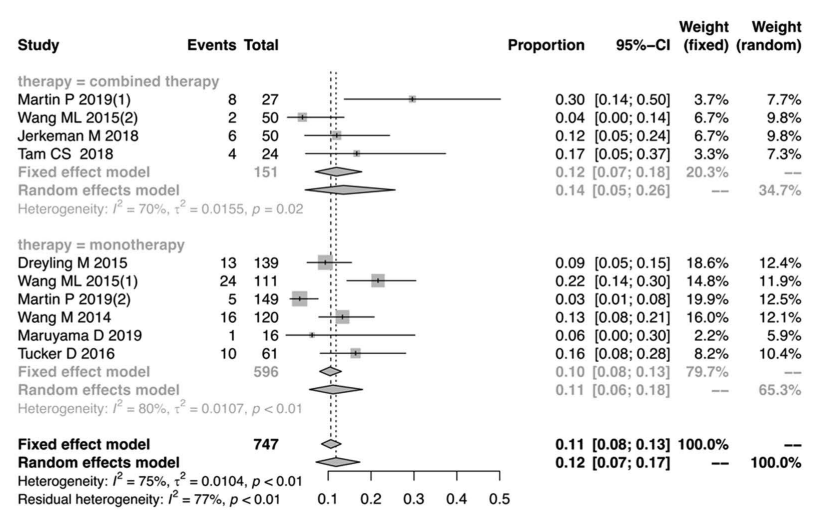

Occurrence rate of thrombocytopenia $\geq$ grade 3

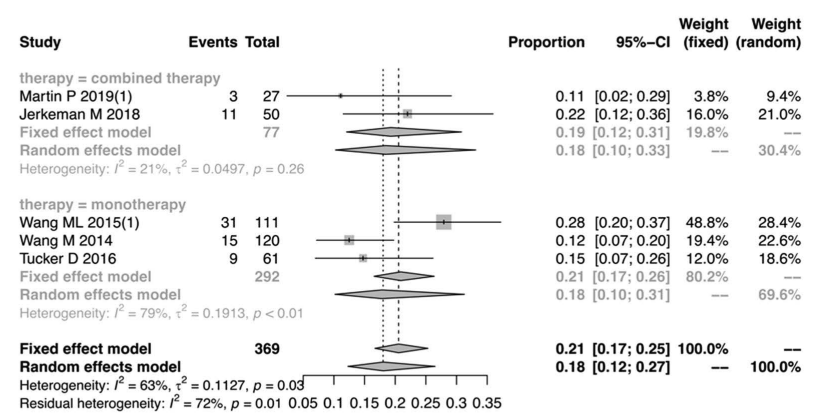

Occurrence rate of infection $\geq$ grade 3

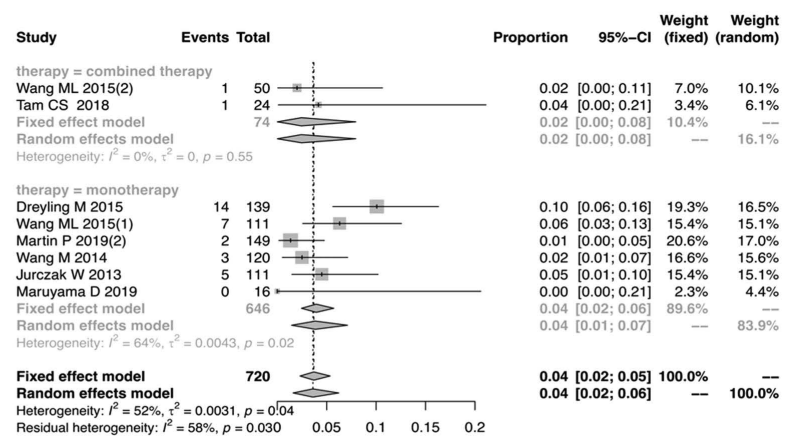

Occurrence rate of bleeding $\geq$ grade 3

Figure 7. Occurrence rate of adverse reactions $\geq$ grade 3 in patients with R/R MCL treated with ibrutinib. Occurrence rate of neutropenia $\geq$ grade 3 was $17 \%$ (95\% CI: $12 \%-25 \%, I^{2}=82 \%, P<0.01$ ), occurrence rate of thrombocytopenia $\geq$ grade 3 was $12 \%$ (95\% CI: $\left.7 \%-17 \%, I^{2}=75 \%, P<0.01\right)$ ), anemia $\geq$ grade 3 was $\left(6 \%\right.$ (95\% CI: $\left.3 \%-9 \%, P^{2}=80 \%, P<0.01\right)$, infection $\geq$ grade 3 was $18 \%$ (95\% CI: $12 \%-27 \%, I^{2}=63 \%, P=0.03$ ), atrial fibrillation $\geq$ grade 3 was $6 \%$ (95\% CI: $\left.4 \%-9 \%, I^{2}=49 \%, P=0.05\right)$, bleeding $\geq$ grade 3 was $4 \%$ (95\% CI: $2 \%-6 \%, P=52 \%, P=0.04)$.

subgroup analysis was conducted according to the treatment regimen. The results showed that the heterogeneity of the combination therapy group was significantly reduced ( $\left.F^{2}=44 \%, P=0.13\right)$ and the ORR was $81 \%$ (95\% CI: $75 \%$ $87 \%$ ), while the ORR of monotherapy group was $74 \%$ (95\% CI: $67 \%-82 \%$ ), and the heterogeneity was high $\left(I^{2}=77 \%, P<0.01\right)$, which might be correlated to different previous treatment regiments, different simplified MCL international 
prognostic index, and various treatment courses. Due to the lack of clinical research data, sub-group stratification analysis could not be repeated. However, the ORR results showed that the therapeutic effect of ibrutinib combined with other drugs was better than that of monotherapy. Therefore, the combination of other drugs for R/R MCL should be considered for patients with poor efficacy of ibrutinib alone or relapse after treatment. In addition to the efficiency, the survival data (PFS, OS) of the patient after treatment was also a critical indicator to evaluate the efficiency of the drug. Hence, statistical analysis was carried out, and the results showed that the two-year PFS rate of ibrutinib in the treatment of R/R MCL patients was $41 \%$ (95\% CI: $31 \%$ - 54\%), while the two-year OS rate was $49 \%$ (95\% CI: $41 \%$ - 57\%). Because only 3 - 4 included studies observed the survival data, and the sample size was small, more clinical data were needed for a comprehensive evaluation of the disease.

According to research reports, ibrutinib was well tolerated during treatment. The majority of the adverse reactions were grades 1 and 2; however, there were reports of adverse reactions of grade 3 and above. The most frequently reported adverse reactions were hematological toxic reactions (including neutropenia, hemoglobin reduction, thrombocytopenia) and atrial fibrillation, bleeding, infection). The analysis revealed that the occurrence rate of neutropenia was higher than other hematological toxicities, and ibrutinib treatment increased the occurrence rate of infection, atrial fibrillation, and bleeding.

In conclusion, ibrutinib shows a satisfactory efficacy in the treatment of $\mathrm{R} / \mathrm{R}$ MCL with tolerable adverse reactions. Therefore, it could be recommended as an effective therapeutic regimen for R/R MCL in clinical practice. Nevertheless, the present study had some limitations: 1) There was only one randomized controlled trial (RCT) on this new drug in the treatment of R/R MCL, and the remaining were cohort studies. Hence, the findings are not as reliable as the conclusions obtained by RCT; 2) Presently, only a few studies have studies this new drug for R/R MCL, but the sample size was small. Thus, expand the sample size to conduct a subgroup analysis of the influence of Ki-67 index, MIPI score, and age on the efficacy, is an urgent requirement to obtain accurate results; 3) The drug resistance, the durability of the drug effect, and the safety of long-term adherence to the drug during the ibrutinib treatment for MCL need to be evaluated for long-term follow-up. Therefore, a large number of clinical studies are essential for a comprehensive assessment of ibrutinib treatment of R/R MCL and to guide the selection of clinical medication.

\section{Acknowledgements}

We would like to express gratitude to the staff of the Jiangxi Key Laboratory of Molecular Medicine and those of Department of Hematology, the Second Affiliated Hospital of Nanchang University.

\section{Authors' Contributions}

M. Cao and J. Li participated in the design and conception of the study. 
M. Cao, X. Y. Zhang, Y. Z. Yang and X. Y. Jiang collected data. M. Cao and Y. S. Tu analyzed and interpreted the data (e.g., statistical analysis, biostatistics, computational analysis). Y. S. Tu and M. Cao wrote the manuscript, which was reviewed and edited by J. Li. M. Cao, X. K. Wang, J. Li and H. J. Tu developed the methodology. Y. Z. Yang, X. K. Wang and X. Y. Jiang provided administrative, technical, or material support (i.e., reporting or organizing data, constructing databases). J. Li and H. J. Tu supervised the study. All authors read and approved the final manuscript.

\section{Funding Sources}

This study is supported by Grants from Natural Science Foundation of Jiangxi Province (20171BAB205045), National Natural Science Foundation of China (81760033).

\section{Ethics Approval}

All procedures followed were in accordance with the ethical standards of the responsible committee on human experimentation (institutional and national) and with the Helsinki Declaration of 1975, as revised in 2008.

\section{Consent to Participate}

Informed consent was obtained from all patients for being included in the study.

\section{Consent for Publication}

All authors approved the manuscript and gave their consent for publication.

\section{Conflicts of Interest}

The authors have no conflicts of interest to declare.

\section{References}

[1] Jain, P. and Wang, M. (2019) Mantle Cell Lymphoma: 2019 Update on the Diagnosis, Pathogenesis, Prognostication, and Management. American Journal of Hematology, 94, 710-725. https://doi.org/10.1002/ajh.25487

[2] Ye, H., Desai, A., Zeng, D., Nomie, K., Romaguera, J., Ahmed, M. and Wang, M.L. (2017) Smoldering Mantle Cell Lymphoma. Journal of Experimental \& Clinical Cancer Research, 36, 185. https://doi.org/10.1186/s13046-017-0652-8

[3] Wang, M.L., Lee, H., Chuang, H., Wagner-Bartak, N., Hagemeister, F., Westin, J., Fayad, L., Samaniego, F., Turturro, F., Oki, Y., Chen, W., Badillo, M., Nomie, K., Rosa, M.D., Zhao, D., Lam, L., Addison, A., Zhang, H., Young, K.H., Li, S., Santos, D., Medeiros, L.J., Champlin, R., Romaguera, J. and Zhang, L. (2016) Ibrutinib in Combination with Rituximab in Relapsed or Refractory Mantle Cell Lymphoma: A Single-Centre, Open-Label, Phase 2 Trial. The Lancet Oncology, 17, 48-56. https://doi.org/10.1016/S1470-2045(15)00438-6

[4] Wang, M.L., Blum, K.A., Martin, P., Goy, A., Auer, R., Kahl, B.S., Jurczak, W., Advani, R.H., Romaguera, J.E., Williams, M.E., Barrientos, J.C., Chmielowska, E., Radford, J., Stilgenbauer, S., Dreyling, M., Jedrzejczak, W.W., Johnson, P., Spurge- 
on, S.E., Zhang, L., Baher, L., Cheng, M., Lee, D., Beaupre, D.M. and Rule, S. (2015) Long-Term Follow-Up of MCL Patients Treated with Single-Agent Ibrutinib: Updated Safety and Efficacy Results. Blood, 126, 739-745.

https://doi.org/10.1182/blood-2015-03-635326

[5] Seda, V. and Mraz, M. (2015) B-Cell Receptor Signalling and Its Crosstalk with Other Pathways in Normal and Malignant Cells. European Journal of Haematology, 94, 193-205. https://doi.org/10.1111/ejh.12427

[6] Herman, S.E., Mustafa, R.Z., Gyamfi, J.A., Pittaluga, S., Chang, S., Chang, B., Farooqui, M. and Wiestner, A. (2014) Ibrutinib Inhibits BCR and NF- $\kappa$ B Signaling and Reduces Tumor Proliferation in Tissue-Resident Cells of Patients with CLL. Blood, 123, 3286-3295. https://doi.org/10.1182/blood-2014-02-548610

[7] Owen, C., Berinstein, N.L., Christofides, A. and Sehn, L.H. (2019) Review of Bruton Tyrosine Kinase Inhibitors for the Treatment of Relapsed or Refractory Mantle Cell Lymphoma. Current Oncology, 26, e233-e240. https://doi.org/10.3747/co.26.4345

[8] Merolle, M.I., Ahmed, M., Nomie, K. and Wang, M. (2018) The B Cell Receptor Signaling Pathway in Mantle Cell Lymphoma. Oncotarget, 9, 25332-25341.

https://doi.org/10.18632/oncotarget.25011

[9] Dreyling, M., Jurczak, W., Jerkeman, M., Silva, R.S., Rusconi, C., Trneny, M., Offner, F., Caballero, D., Joao, C., Witzens-Harig, M., Hess, G., Bence-Bruckler, I., Cho, S.-G., Bothos, J., Goldberg, J.D., Enny, C., Traina, S., Balasubramanian, S., Bandyopadhyay, N., Sun, S., Vermeulen, J., Rizo, A. and Rule, S. (2016) Ibrutinib versus Temsirolimus in Patients with Relapsed or Refractory Mantle-Cell Lymphoma: An International, Randomised, Open-Label, Phase 3 Study. The Lancet, 387, 770-778. https://doi.org/10.1016/S0140-6736(15)00667-4

[10] Wang, M., Goy, A. and Martin, P. (2014) Efficacy and Safety of Single-Agent Ibrutinib in Patients with Mantle Cell Lymphoma Who Progressed after Bortezomib Therapy. Blood, 124, 4471. https://doi.org/10.1182/blood.V124.21.4471.4471

[11] Lau, J., Ioannidis, J.P. and Schmid, C.H. (1997) Quantitative Synthesis in Systematic Reviews. Annals of Internal Medicine, 127, 820-826. https://doi.org/10.7326/0003-4819-127-9-199711010-00008

[12] Martin, P., Bartlett, N.L., Blum, K.A., Park, S., Maddocks, K., Ruan, J., Ridling, L., Dittus, C., Chen, Z., Huang, X., Inghirami, G., DiLiberto, M., Chen-Kiang, S. and Leonard, J.P. (2019) A Phase 1 Trial of Ibrutinib plus Palbociclib in Previously Treated Mantle Cell Lymphoma. Blood, 133, 1201-1204. https://doi.org/10.1182/blood-2018-11-886457

[13] Jerkeman, M., Eskelund, C.W., Hutchings, M., Räty, R., Wader, K.F., Laurell, A., Toldbod, H., Pedersen, L.B., Niemann, C.U., Dahl, C., Kuitunen, H., Geisler, C.H., Grønbæk, K. and Kolstad, A. (2018) Ibrutinib, Lenalidomide, and Rituximab in Relapsed or Refractory Mantle Cell Lymphoma (PHILEMON): A Multicentre, Open-Label, Single-Arm, Phase 2 Trial. The Lancet Haematology, 5, e109-e116. https://doi.org/10.1016/S2352-3026(18)30018-8

[14] Martin, P., Goy, A., Ramchandren, R., Ferrante, L., Londhe, A., McGowan, T. and Bartlett, N.L. (2019) To the Editor, a Multicenter, Open-Label, Early Access Treatment Protocol for Ibrutinib in Patients with Relapsed or Refractory Mantle Cell Lymphoma. Journal of Oncology Pharmacy Practice, 25, 1027-1030. https://doi.org/10.1177/1078155219831435

[15] Jurczak, W., Rule, S., Martin, P., Auer, R., Kahl, B.S., Giza, A., Jachimczak, B., Advani, R.H., Romaguera, J., Williams, M., Barrientos, J., Chmielowska, E., Radford, J., Stilgenbauer, S., McGreivy, J., Clow, F., Beaupre, D.M., Kunkel, L., Goy, A., Blum, K.A., Jędrzejczak, W. and Wang, M.L. (2013) Inhibitor kinazy Brutona u chorych z 
nawrotowym lub opornym na leczenie chłoniakiem z komórek płaszcza-wyniki międzynarodowego, wieloośrodkowego, badania II fazy z ibrutynibem (PCI-32765) EHA Encore. Acta Haematologica Polonica, 44, 314-318.

https://doi.org/10.1016/j.achaem.2013.07.013

[16] Maruyama, D., Nagai, H., Fukuhara, N., Kitano, T., Ishikawa, T. and Nishikawa, T. (2019) Final Analysis of a Phase II Study of Ibrutinib in Japanese Patients with Relapsed/Refractory Mantle Cell Lymphoma. Journal of Clinical and Experimental Hematopathology, 59, 98-100. https://doi.org/10.3960/jslrt.19006

[17] Tam, C.S., Anderson, M.A., Pott, C., Agarwal, R., Handunnetti, S., Hicks, R.J., Burbury, K., Turner, G., Di Iulio, J., Bressel, M., Westerman, D., Lade, S., Dreyling, M., Dawson, S.J., Dawson, M.A., Seymour, J.F. and Roberts, A.W. (2018) Ibrutinib plus Venetoclax for the Treatment of Mantle-Cell Lymphoma. The New England Journal of Medicine, 378, 1211-1223. https://doi.org/10.1056/NEJMoa1715519

[18] Sharman, J.P., Farber, C.M., Mahadevan, D., Schreeder, M.T., Brooks, H.D., Kolibaba, K.S., Fanning, S., Klein, L., Greenwald, D.R. and Sportelli, P. (2017) Ublituximab (TG-1101), a Novel Glycoengineered Anti-CD 20 Antibody, in Combination with Ibrutinib Is Safe and Highly Active in Patients with Relapsed and/or Refractory Chronic Lymphocytic Leukaemia: Results of a Phase 2 Trial. British Journal of Haematology, 176, 412-420. https://doi.org/10.1111/bjh.14447

[19] Tucker, D., Vandenberghe, E., Morley, N., Bowles, K. and Rule, S. (2016) Real World Experience of Ibrutinib in Mantle Cell Lymphoma-Prospective Multi-Centre Data from 61 Patients Treated for MCL with Ibrutinib (Single Agent) via the Expanded Access Programme in Great Britain and Ireland: 207. British Journal of Haematology, 173, 86-87.

[20] Dreyling, M., Aurer, I., Cortelazzo, S., Hermine, O., Hess, G., Jerkeman, M., Le Gouill, S., Ribrag, V., Trněný, M., Visco, C., Walewski, J., Zaja, F. and Zinzani, P.L. (2018) Treatment for Patients with Relapsed/Refractory Mantle Cell Lymphoma: European-Based Recommendations. Leukemia \& Lymphoma, 59, 1814-1828. https://doi.org/10.1080/10428194.2017.1403602

[21] Maddocks, K. (2018) Update on Mantle Cell Lymphoma. Blood, 132, 1647-1656. https://doi.org/10.1182/blood-2018-03-791392

[22] Rule, S., Dreyling, M., Goy, A., Hess, G., Auer, R., Kahl, B., Cavazos, N., Liu, B., Yang, S., Clow, F., Goldberg, J.D., Beaupre, D., Vermeulen, J., Wildgust, M. and Wang, M. (2017) Outcomes in 370 Patients with Mantle Cell Lymphoma Treated with Ibrutinib: A Pooled Analysis from Three Open-Label Studies. British Journal of Haematology, 179, 430-438. https://doi.org/10.1111/bjh.14870 